\title{
Research on the Strategies of Urban Organic Renewal under the Background of Rail Transit
}

\author{
Di Wang ${ }^{1, a}$ \\ ${ }^{1}$ School of Highway, Chang'an University, Xi'an, 710064, China \\ ${ }^{a}$ email
}

Keywords: Urban organic renewal, Rail transit, Organic regeneration

\begin{abstract}
At present, as an important way to solve the problem of urban crowded traffic, rail transit has set off a large-scale construction boom in China. On the one hand, the original city spatial pattern cannot adapt to the new city traffic demand, which will inevitably bring a new round of city renewal; on the other hand, the construction of city rail traffic should also reach the city organic renewal goals. This paper discusses the urban organic renewal strategy under the background of rail transit to provide some references for the relative researchers.
\end{abstract}

\section{Concept of Urban Organic Renewal}

As a kind of self-regulating mechanism, urban renewal appears in every stage of urban development. In 1950s, some developed countries in Europe and the United States discovered the phenomenon of reverse urbanization which brought about the problem of hollow city. Many countries are trying to take all kinds of measures to restore the vitality of the city, attracting residents to return to the city. Under this background and the support of related research, urban renewal has become a social engineering discipline. The organic renewal of the city is the necessary reconstruction of the region which is not suitable for the integration of urban social life in the city. It mainly includes the transformation of the objective entities, such as buildings, as well as the transformation and continuation of various ecological environment, space environment, cultural environment, visual environment, recreation environment and so on. The idea of organic renewal emphasizes to follow the inherent law of urban development to adapt to the texture of the city, and to explore the sustainable development of the city. It mainly contains three meanings. The city is the carrier of citizen's life and work. It is also a collection of street, road and other organizational details, and its relationship with the various components of the relationship between organisms and their own cells, such as the same, are symbiotic, interdependent. The courtyard and block of the residents are the city cells and the city organizations. The same as the metabolism of organisms, the structure of the city itself is also the inevitable development of the replacement of the new city. But in any case, the new structures of the city details still need to comply with the original urban layout. The metabolism of an organism is natural, continuous, and systematic in its internal order and regularity. Urban renewal construction should also be made in its own order and law to obtain normal development.

\section{Objectives of Urban Organic Renewal under the Background of Rail Transit}

Objective of Smooth Traffic. We should provide the city with a variety of modes of transport composd of the establishment of rail transportation as the backbone of the city and the common bus convergence of public transport system to improve the urban bus sharing rate. The city is a complex giant system, which involves all aspects of society, economy and culture and so on. As the adjustment mechanism in the process of urban development, the positive significance of urban renewal is to prevent the decline of the city and promote the development of the city. Rail transportation as the backbone of the city transportation, the construction goals include improving the city traffic level, promoting the city function, city spatial structure optimization, to create a good city environment, promote the sustainable development of city society, economy, culture and ecological environment and improve the overall competitiveness of the city. In the deep sense, urban renewal should be 
regarded as an important part of the whole social development work. It should be a comprehensive and long-term standard for the whole city. The general guiding ideology should be to improve the urban function, to adjust the urban structure to improve the urban environment, to update the material facilities and to promote urban civilization.

Objective of Economic Development. As the center of the renewal of the urban renewal, the economic development objective includes many factors. The objective factors include the urban industrial structure, industrial technology, industrial management model, which directly affect the economic benefits of the city. Through the urban renewal to promote the adjustment of the industrial layout and the renewal of the urban traffic system in the city, the city's industrial upgrading and the development of urban economy will be promoted. Urban construction around the subway station forms an ideal development model. Within the core area of the site to do high-intensity land development, the strength of the hinterland to do outside the development, thereby enhancing the core area of the station and the number of people living and employment, increase passenger flow, play the value of the hinterland of the land. Based on the field investigation of the environmental parameters in the subway station, this paper analyzes the relationship between the thermal sensation of human body and the effective temperature difference in the transition between different environments in the hub, and establishes the prediction model of thermal sensation under the transition condition. The city renewal in accordance with the principle of people-oriented, the purpose is to provide convenient services for the residents to create high-quality social and physical space, so that the living environment and living conditions of peace, security, health, comfort and convenience. Generally speaking, the evaluation indexes are the per capita living space, the per capita green space, the per capita traffic conditions, the level of per capita public service facilities and the level of per capita infrastructure. At the same time, combined with the development of underground space, increase the utilization of urban land. High density, three-dimensional, three-dimensional space and three-dimensional pedestrian area, in addition to the ground as the base city activities, there are underground city activities and activities of city air base base construction of city space. Multi-function is an important guarantee to promote regional prosperity. Commercial, residential, office, leisure and service functions are complementary to each other, and promote each other. These functional spaces mix and intersperse to make it more convenient for people's behavior to stimulate the vitality of the city.

Objective of Environment Optimization. Urban renewal, which is based on environmental sustainability, tends to environmental regulation and environmental protection. From the perspective of the overall ecological environment protection of the city, the adjustment of industrial layout, the organization of environmental space system. We realize the comprehensive and balanced development of economic development and environmental protection. The objective factors include urban air quality, water quality, water quality, urban noise, urban sewage treatment rate and urban garbage harmless treatment rate. City rail transit construction, generally need to have certain environmental pollution, be busy at putting up installations, and noise pollution, water and air pollution etc.. However, any form of urban renewal must be carried out in the context of environmental optimization. The negative effects of rail transit on the environment shall be eliminated. We establish the comfort evaluation model of urban rail transit hub. According to the research results of thermal sensation of the junction, the thermal comfort of passengers is analyzed, and then the comfort of the hub is analyzed, and then the comfort evaluation method is obtained. Subway is not only a means of transport, but also a civilization, a way of life. Let us go home subway way more fun, we will have more time to enjoy life, subway construction of the complete circle, will make our life more comfortable. Control the noise source, reduce the noise transmission, reduce the volume of high decibel sound, and avoid the noise to the passengers. On the subway space existing high decibel value of sound in different degrees of transformation, for example by adding shielding door to strengthen maintenance and improve their vehicle muffler. 


\section{Strategies of Urban Organic Renewal under the Background of Rail Transit}

Traffic Strategy. Traffic system updates should not only stay in the road update level, should also include transportation convenient transport facilities and spacious hub site, three-dimensional and humanized to provide a safe and comfortable space for people of the city. Influence of city rail traffic under the city center district renewal by the location and traffic conditions usually have the function of commercial, office, residential, transportation, culture, recreation and other, so the renewal planning should be combined with the city rail traffic, providing three-dimensional public space for different people, the integration of system form three the level of the ground, the ground and underground. The use of multidimensional space and cascading style with the integration of city environment and strengthen the relationship between rail transit and city renewal and promote land intensive use of city three-dimensional mixing function, and thus achieve the goal of development of regional integration. We fully understand and use the land use function and the influence on the traffic in the city, through the late planning regulation actively, promote the renewal and development of surrounding areas of the rail transit station to help track traffic using the direction of development, is of positive significance to the implementation of bus priority target. In orbit City, rail transportation is the most convenient way to commute, traffic convenience brought by rail transit planning, should be the number of areas surrounding the rail transit station employment as an important indicator, by increasing the number of jobs, not only can bring more commuter flow, but also can improve the internal block the activity, to provide better services for tourists and local residents.

Economic Strategy. China has a large population base, the scarcity of land resources and other characteristics. Especially in the city center, this feature is more prominent. Therefore, the urban renewal in China is not suitable for the low density sprawl development in North America, but should be combined with urban rail transit. The compact central urban renewal is mainly reflected in the intensive use of land resources, the focus of the layout of urban functional elements, strengthen the management of urban space growth, and promote the use of high-density urban land. In the planning process, we should save the urban construction land, in the limited urban space layout of the higher density of the industry and population, improve the efficiency of land resource allocation. According to the location of the land, the surrounding landscape, traffic and other factors, in-depth investigation of the needs of the users of the area, the rational division of regional and land allocation function. Updated planning should also be a reasonable mix of land functions to facilitate the public to use, and stimulate diverse urban life. But also should pay attention not to increase the volume and density over land, to avoid aggravating urban heat island effect, should be guided by the concept of sustainable development, rational development and utilization of the original land, to meet the needs of the rapid development of our city. Land use pattern and compact concentration should also and perfect coordination of city public transportation system, reduce the use amount of the car, with convenient public transport to transport a large number of people, to support public transportation especially the city rail transit, walking and bicycle advocate green transportation. Compact urban renewal model needs to provide better and more public service facilities and municipal infrastructure to meet the needs of a large number of people gathered. To compact the use of land and the flow of people gathered to stimulate the vitality of the city to promote the prosperity of the city.

Environment Strategy. We should design a sound signal system with high comfort and unity. It can not only achieve the effect of conveying information, but also improve the quality of the environment. In clear and effective sound information, improve the overall quality of the sound environment concept, automatic ticket vending machine and the subway facilities in the multifunctional kiosk. The lobby and platform car voice prompts and other aspects of the design of sound signal. The barrier free design of public environment is an important reflection of building a harmonious society with love and care, and an important factor to measure the quality of urban life. The voice of the world is an indispensable part of our daily life, is an important support element of our lives. Sound environment refers to people's living environment. The quality of the sound environment is directly related to the quality of our lives. Before the industrial revolution, the world of human 
hearing was mainly composed of natural sounds. The subway space should be considered from the sound point of view, increase the accessibility of some facilities design to create a safe, convenient and comfortable subway space. In the renewal of a city as far as possible to provide diversification of city function, such as commercial, office, residential culture, etc., to build a prosperous and modern city environment, make people more willing to gather here; at the same time, the basic elements required to retain the beautiful city life, such as the harmony of neighborhood and convenient transport links and various cultural facilities, provide a suitable living environment for the people. China's per park and green area much less than many countries in the world. We should pay attention to the design and construction of the city renewal street, square, park, public green space, to create a sustainable city environment. Water environment management, air quality, waste disposal, environmental health and other aspects have been very good change. People attach importance to environmental protection.

\section{Conclusion}

The large scale construction of rail transit in China makes the urban development face new features and new trends, which has injected new impetus for urban renewal. In this paper, the strategies of urban organic renewal under the background of rail transit are given. In fact, urban rail transit and urban renewal are very complex systems, involving the knowledge of urban planning, rail transit planning, land use planning and so on. The urban renewal strategies under the background of rail transit needs further study.

\section{References}

[1] Luan Bin, Sun Hui, The Organic Regeneration of City Centers Under the Influence of Rail Transit Development [J]. Urbanism and Architecture, 2011(8): 32-35.

[2] Zhuo Jian, Urban Renewal Strategy of Metro Station Vicinity [J]. Planners, 2016, 32(10): 11-16.

[3] Bai Yunxi, Lu Wei, Liu Lianlian, Urban Renewal Planning in City Centre Based on Three-Dimensional Transport: A Case Study of Shiodome in Tokyo, Japan [J]. City Planning Review,

2014(7): 76-83.

[4] Wang Teng, Cao Xinjian, Strategies About Urban Redevelopment in Urban Rail Transit Station Areas-- Based on Studies of Domestic and Foreign Large Cities [J]. Urban Mass Transit, 2011(11):33-39+56. 